\title{
Analysis on Influence Factors of Air Ejection's Interior Ballistic Characteristics Based on Real Gas Effects
}

\author{
Lei Xie $^{1, a, *}$, Qinhe Gao ${ }^{1, b}$, Yajun Shao ${ }^{1, c}$ \\ ${ }^{1}$ Xi’an High-Tech Research Institute, Xi’an, Shaanxi, China \\ a 870577035@qq.com, b qhgao201@126.com, c 1943084179@qq.com \\ *corresponding author
}

Key words: Interior ballistic model, Runge-kutta method, Real gas effects, Factor analysis.

\begin{abstract}
A straight-tube type high pressure air ejection device was studied in this paper, aiming at impacts that structure parameters, gas source characteristics and environmental factors on the interior ballistic characteristics of ejection system and considering the real gas effects of compressed air, an interior ballistic mathematical model of high-pressure-air ejection was established. What's more, the influence law of multiple variables including air pressure, the control valve size and initial temperature to interior ballistic characteristic curves were simulated, calculated and analyzed and it was concluded that these three parameters influence the interior ballistic parameters differently. Finally, it will benefit the missile ejection as these parameters being within a reasonable range and work cooperatively.
\end{abstract}

\section{Introduction}

High pressure air ejection has its distinctive features and is applied in special occasions ${ }^{[1]}$. RUI Shou-zhen and XING Yu-ming ${ }^{[2]}$ concluded that high pressure air ejection's temperature, pressure change more smoothly compared to other modes of ejection by analyzing and comparing interior ballistic characteristics of different modes of ejection force; Aiming at the cylinder-type ejection device, YANG Feng-bo and MA Da-wei ${ }^{[3]}$ constructed an interior ballistic mathematical model of high-pressure air ejection considering the real gas effects, concluded that power capability of high pressure air varies from the ideal gas. Finally they demonstrated the necessity of research on the real gas effects. Considering the real gas effects of compressed air, an interior ballistic mathematical model of high pressure air ejection was established in this paper. Moreover, influence laws of air pressure, the control valve size and initial temperature on the interior ballistic characteristics were researched and analyzed.

\section{High pressure air ejection process and physical model}

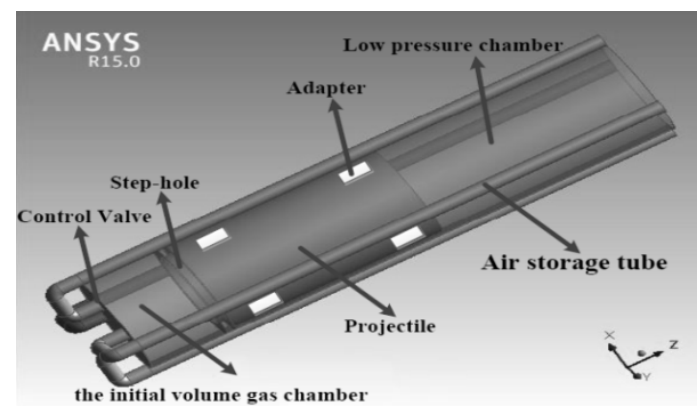

Fig.1 Structure graph of a straight-tube type high pressure air ejection device.

Structure graph of a straight-tube type high pressure air ejection device is shown in Fig.1. High pressure air is stored in the air storage tubes. When launching, it flows into the initial volume gas chamber through control valves. When the total thrust, which is composed of pressure of the 
compressed air in initial chamber and the atmosphere, is bigger than the resistance including projectile's gravity, friction force and so on, the projectile is promoted to go up due to the air' motivation. Adapters are used to restrict the projectile's move in radial direction.

\section{Interior ballistic mathematical model of high pressure air ejection}

To simplify problems, assumptions are made as below:

1) Air leakage phenomenon is inexistent;

2) The process is of heat insulation and constant entropy;

3) The projectile diameter is similar to diameter of the launch tube;

4) Viscosity is unconcerned.

According to the mass and energy equations of high pressure and low pressure chambers, flow equations and the Virial equation of corresponding state ${ }^{[4-7]}$, the mathematical model is achieved as below with referring to the documentation 3rd:

$$
\left\{\begin{array}{l}
\frac{d}{d t}\left(\rho_{1} V_{1}\right)=-Q_{m}, \\
\frac{d}{d t}\left(\rho_{1} V_{1} u_{1}\right)=-Q_{m} h_{1}, \\
p_{1}=\frac{R T_{1}}{V_{m 1}}\left(1+\frac{B_{1}}{V_{m 1}}+\frac{C_{1}}{V_{m 1}^{2}}\right), \\
\frac{d m_{2}}{d t}=Q_{m}, \\
\frac{d}{d t}\left(m_{2} u_{2}\right)=Q_{m} h_{1}-S_{t} p_{2} \frac{d l}{d t}, \\
m_{e} \frac{d V_{2}}{d t}=\left(p_{2}-p_{a}\right) S_{t}-1.2 m_{e} g \sin (\alpha), \\
p_{2}=\frac{R T_{2}}{V_{m 2}}\left(1+\frac{B_{2}}{V_{m 2}}+\frac{C_{2}}{V_{m 2}^{2}}\right) .
\end{array}\right.
$$

In the above equations, the subscript 1 represents parameters of the high pressure chamber, while 2 represents parameters of the low pressure chamber; $\rho$ represents gas density; $V_{1}$ represents volume of gas in the high pressure chamber; $m$ represents gas quality; $l$ represents the travel; $m_{e}$ represents projectile quality; $v_{2}$ represents the velocity; $p_{a}$ represents the atmosphere pressure; $\alpha$ represents launch angle as $90^{\circ}$; $S_{t}$ represents area of the projectile bottom; $g$ represents acceleration of gravity.

\section{Interior ballistic characteristics and influence factors analysis}

Basing on the above mathematical model, four-order Range-Kutta method is used and numerical programs are written in the Matlab software to calculate. By using the simple variable method, effects of air source pressure, the control valve size and initial temperature to the interior ballistic characteristics are analyzed. Part parameters used are showed in Table 1.

\subsection{Air source pressure effects}

As the air source pressure and initial air density have positive correlation, air density is studied instead. Initial air density values are set as $\rho_{H}=420 \mathrm{~kg} / \mathrm{m}^{3}, \rho_{H}=462 \mathrm{~kg} / \mathrm{m}^{3}, \rho_{H}=508.2 \mathrm{~kg} / \mathrm{m}^{3}, \rho_{H}=559.02$ $\mathrm{kg} / \mathrm{m}^{3}$. Curves of the velocity change under different initial source pressure values are shown in Fig.2, while the overload change curves are shown in Fig.3. 
Table 1 Reference parameters used.

\begin{tabular}{|c|c|c|}
\hline Parameters & Symbols & Values \\
\hline critical density & $\rho_{C} /[\mathrm{kg} / \mathrm{m} 3]$ & 342.6034 \\
\hline critical temperature & $\left.T_{c} / \mathrm{K}\right]$ & 132.5306 \\
\hline critical pressure & $\left.P_{c} / \mathrm{MPa}\right]$ & 3.7860 \\
\hline acentric factor; time & $\omega ; \mathrm{t} /[\mathrm{s}]$ & $0.031 ; 0.77$ \\
\hline molar mass & $\mathrm{M} /[\mathrm{kg} / \mathrm{mol}]$ & 0.028959 \\
\hline Standard atmosphere pressure & $P a /[\mathrm{MPa}]$ & 101325 \\
\hline molar gas constant & $R /[\mathrm{J} /(\mathrm{mol} \cdot \mathrm{K})]$ & 8.3145 \\
\hline projectile's mass & $m e / \mathrm{kg}]$ & 31199.9 \\
\hline flow modificatory coefficient & $\mu x$ & 0.96 \\
\hline air adiabatic index & $k$ & 1.4 \\
\hline gas constant of air & $R g /[\mathrm{J} / \mathrm{kg} \cdot \mathrm{K})]$ & 287 \\
\hline specific heat at constant volume & $\left.C_{V i} \Lambda \mathrm{J} /(\mathrm{kg} \cdot \mathrm{K})\right]$ & 716 \\
\hline volume of the initial volume gas chamber & $\left.V_{H} / \mathrm{m} 3\right]$ & 2.4 \\
\hline initial volume of the low pressure chamber & $\left.V_{L 0} / \mathrm{m} 3\right]$ & 0.96 \\
\hline
\end{tabular}

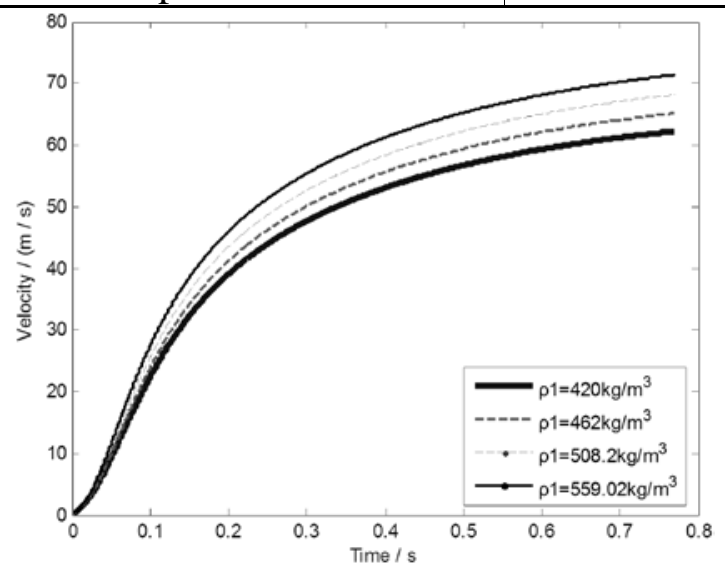

Fig.2 Velocity change under different air pressure values.

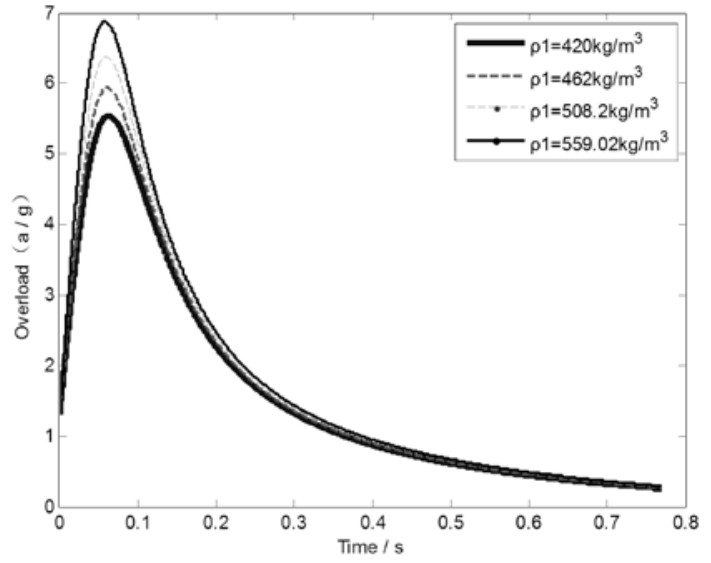

Fig.3 Overload change under different air pressure values.

In Fig.2, velocity change trend is shown as below: it increases rapidly at first, then becomes smooth gradually. What's more, with the increase of high-pressure chamber pressure, velocity of the projectile becomes more acutely and the final speed will be larger. It is shown in Fig. 3 that at the beginning stage, the overload increases very quickly, then it decreases rapidly in the same way; with the increase of high-pressure chamber pressure, the overload has a higher peak and acuter changes.

\subsection{The control valve size effects}

The control valve's area values are set as $A_{k}=0.0236 \mathrm{~m}^{2}, A_{k}=0.026 \mathrm{~m}^{2}, A_{k}=0.0286 \mathrm{~m}^{2}, A_{k}=0.0314 \mathrm{~m}^{2}$. 
Curves of the mass flow rate change under different control valve sizes are shown in Fig.4, while curves of the travel change are shown in Fig.5.

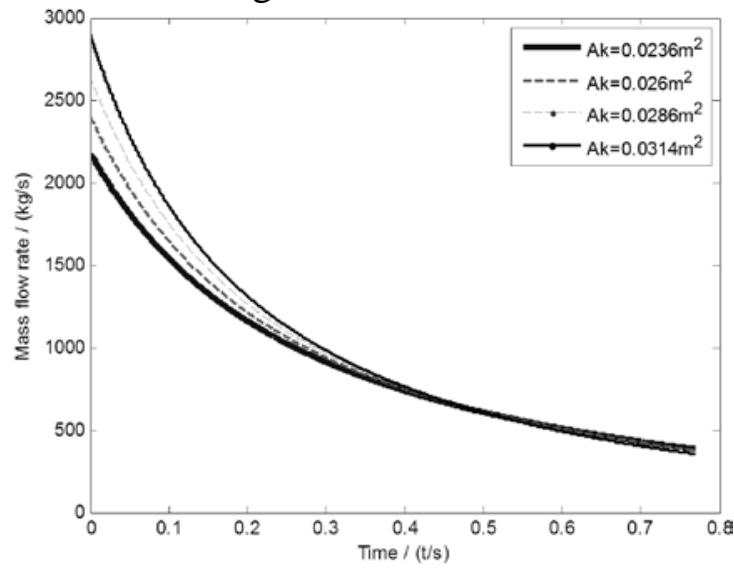

Fig.4 Mass flow rate change under different valve sizes.

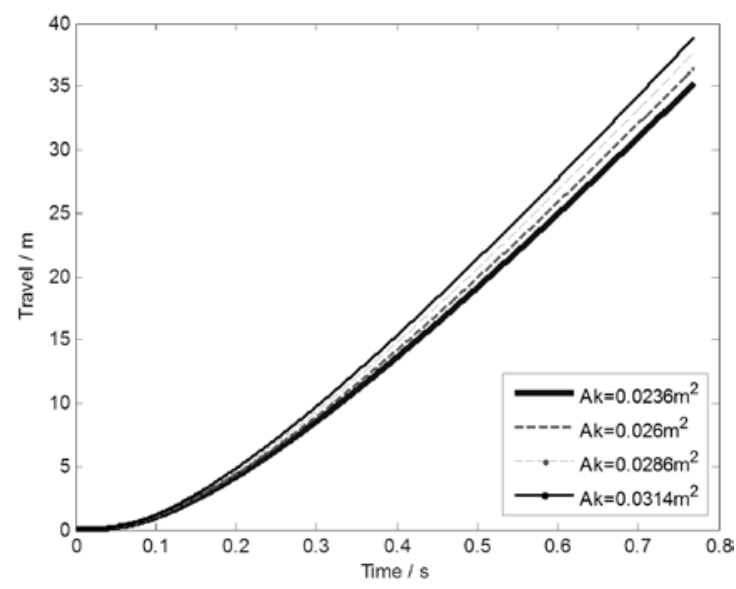

Fig. 5 Travel change under different valve sizes.

It is shown in Fig.4 that a larger-sized control valve causes the increase of gas mass flow's initial value and acuter changes. It is shown in Fig. 5 that the total change tendency of the projectile's travel is as below: at first, it moves slowly and then the change rate starts to increase. What's more, increase of the control valve size could make the raise of the projectile's change rate at a certain extent.

\subsection{Initial temperature effects}

Initial temperature of gas chambers are set as $T_{H}=T_{L}=293.15 \mathrm{~K}, T_{H}=T_{L}=322.47 \mathrm{~K}, T_{H}=T_{L}$ $=354.71 \mathrm{~K}, T_{H}=T_{L}=390.18 \mathrm{~K}$. Curves of the pressure change in low pressure chamber under different initial temperature values are shown in Fig.6, while curves of mass of the low-pressure chamber air are shown in Fig.7 


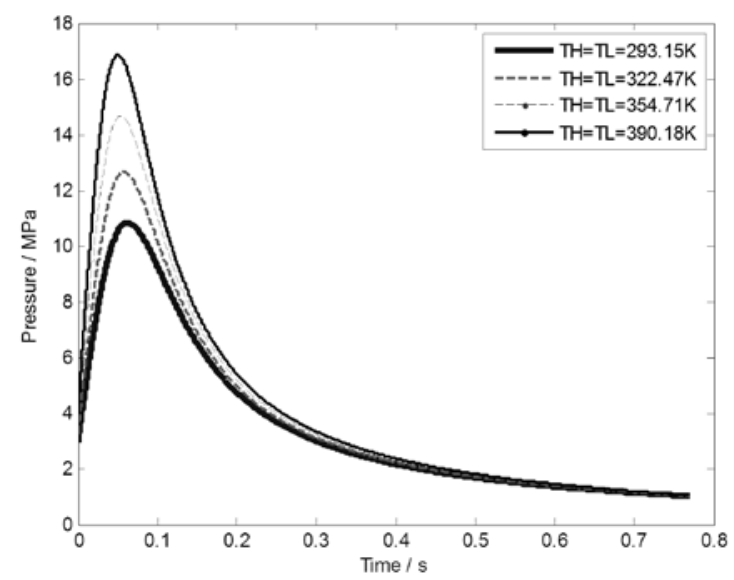

Fig.6 Pressure change under different temperature values.

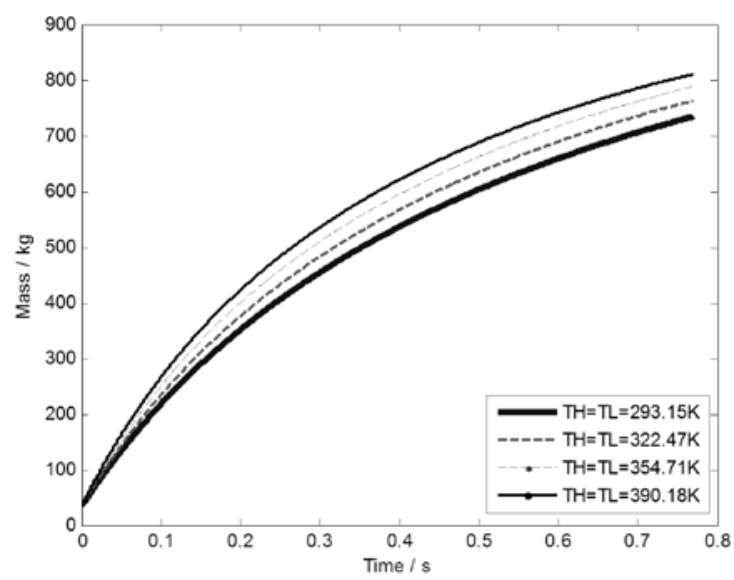

Fig.7 Air mass change under different temperature values.

It is shown in Fig.6 that firstly pressure of the low-pressure chamber increases rapidly and reaches the peak in the first 0.07 seconds, then it reduces quickly and tends to be smooth; a higher pressure peak and an acuter change arise due to the increased temperature. It is shown in Fig.7 that mass of the low-pressure chamber air tends to be increased and its increasing rate decreases slowly as time flows. After accomplishment of establishing the low-pressure chamber pressure which means the move of the projectile, a higher temperature leads to more gas flowing into the low-pressure chamber.

\section{Conclusion}

Effects that air source pressure, the control valve size and initial temperature to interior ballistic characteristics are analyzed in the essay. Conclusions are got as below:

(1) An increase in air source pressure leads to acuter overload which is bad to the projectile's moving out of the tube smoothly. But under the condition of higher source pressure, the device could gain larger ejection power with an increase in velocity. In conclusion, under the condition that overload abilities of the projectile is allowed, an increase in source pressure will be beneficial to performances of the device.

(2) Within limits, a larger sized control-valve leads to more mass flow of gas flowing through it which makes the travel change more quickly. It shows that the control valve size affects some important characteristics like the ejection travel to some extent. Suitable size of the control valve is preferable.

(3) Acuter changes and a higher peak happen to the low-pressure chamber pressure under the condition of higher initial temperature; moreover, higher temperature could promote the gas flowing from the high-pressure chamber to the low-pressure which will enhance the utilization ratio of the high-pressure air. 


\section{References:}

[1] Dacheng Tan. Interior Ballistics of Catapults[M]. Beijing: Beijing Institute of Technology Press, 2015.

[2] Shouzhen Rui and Yuming Xing. Canparative Studies of Interior Ballistic Performance Among Severa1 Missile Eject Power Systems[J]. Journal of Beijing University of Aeronautics and Astronautics, 2009, 35(6):766-770.

[3] Fengbo Yang, Dawei Ma, Fan Yang. Interior Ballistics Modeling and Calculation of High-pressure Ejection Device[J]. Acta Armamentarii, 2013, 34(5):527-534.

[4] Meng L, Duan Y Y. Correlations for second and third virial coefficients of pure fluids[J]. Fluid Phase Equilibria, 2004, 226: 109-120.

[5] Chueh P L, Prausnitz J M. Third virial coefficients of nonpolar gases and their mixtures[J]. AIChE Journal, 1967, 13 ( 5) : 896-902.

[6] Orbey H, Vera J H. Correlation for the third virial coefficient using Tc,Pc and as parameters[J]. AIChE Journal, 1983, 29( 1) :107-113.

[7] Tsonopoulos C. An empirical correlation of second virial coefficients[J]. AIChE Journal, 1974, 20(2) :263-272. 